\title{
A INTERVENÇÃO ESTATAL COMO PRESSUPOSTO NECESSÁRIO PARA A EFETIVIDADE E MANUTENÇÃO DOS DIREITOS SOCIAIS
}

\section{Alan Martinez Kozyreff ${ }^{1}$}

\section{RESUMO}

Este trabalho tem a intenção de expor a transição do modelo de Estado Liberal para o Estado Intervencionista-social, mormente sobre o enfoque da Constituição do México, de 1917 e a de Weimar, de 1919 e suas repercussões na Constituição do Brasil, de 1934. A metodologia utilizada foi a pesquisa de livros, artigos científicos, dissertações de mestrado, teses de doutorado, consultas de leis e constituições por meio da internet. $\mathrm{O}$ artigo se encerra com algumas considerações em torno da intervenção estatal para assegurar uma política social ativa.

Palavras-chave: Constituição Weimar de 1919, Constituição México de 1917, Estado Social, Estado Liberal, Direitos Sociais.

\section{STATE INTERVENTION AS AN ASSUMPTION NEEDED FOR EFFECTIVENESS AND MAINTAINING SOCIAL RIGHTS}

\begin{abstract}
This paper intends to expose the transition from the Liberal State model to the InterventionistSocial State, especially on the approach of the Constitution of Mexico in 1917 and the Weimar in 1919 and its repercussions of the Brazilian Constitution in 1934. The methodology used was the research in books, scientific articles, master's dissertations, doctoral theses, consultations of laws and constitutions through the internet. The article concludes with some considerations about the necessity of the state intervention to ensure an active social policy.
\end{abstract}

Keywords: Constitution of Weimar 1919, Constitution of Mexico 1917, Social State, Liberal State, Social Law.

\section{INTRODUÇÃO}

O embate entre o liberalismo e o intervencionismo estatal acompanha a sociedade em grande parte da sua história e nota-se essa tensão em diversos aspectos social como na vida privada do cidadão, na economia e na relação de trabalho.

No entanto, um tema bastante atual, que reflete de forma importante na vida das pessoas é a intervenção do Estado na garantia de direitos sociais, em especial em momentos onde a palavra crise econômica é ouvida todos os dias e em diferentes idiomas.

\footnotetext{
${ }^{1}$ Advogado. Especialista em Direito do Trabalho. Mestrando em Direito da Saúde pela Universidade Santa Cecília. E-mail: alankozyreff@gmail.com
} 
Sem utilizar posições extremadas, pois foge da intenção do presente texto, de um lado notam-se defensores da livre iniciativa, ou seja, aqueles que entendem uma liberdade ampla, com intervenção estatal mínima, sob o fundamento que a regulação do Estado engessa a prosperidade econômica.

Para este pensamento, ou seja, assegurando a livre iniciativa, as empresas prosperariam, gerando riqueza e renda, ocasionando crescimento econômico e social, fazendo com que toda a sociedade evolua.

Por outra banda, existem aqueles que entendem o Estado como um regulador da vida em sociedade, devendo ocorrer a interferência em matérias onde o ente estatal entende sensível, notadamente na garantia da equivalência de forças entre partes desiguais, ou seja, assegurando a igualdade.

O presente trabalho apresenta antecedentes históricos importantes entre o embate liberalismo econômico e intervencionismo estatal, considerando os direitos sociais, em especial os de natureza trabalhista.

Inicialmente analisaremos alguns aspectos da Revolução Francesa, a tomada do poder pela burguesia e como este fato refletiu na configuração estatal e na economia produtiva, desembocaremos na Revolução Industrial, ápice do liberalismo econômico e qual a repercussão na sociedade e na relação de trabalho.

Analisaremos a reação a este movimento, como as Constituições do México, de 1917 e a de Weimar, de 1919 que, reconhecidamente, rompem com o modelo constitucional liberal para a instituição do constitucionalismo social.

Ao final, será concluída sobre a participação estatal, como ente ativo e intervencionista na garantia de direitos sociais.

\section{METODOLOGIA}

O método utilizado é o descritivo, analisando fatos históricos para uma conclusão específica. A abordagem é qualitativa e a pesquisa bibliográfica ocorreu a partir de livros e artigos científicos pertinentes à temática em questão.

\section{ANTECEDENTES HISTÓRICOS}

Bobbio (1992, p. 51) aponta que em um dos seus últimos escritos, Immanuel Kant questiona se o gênero humano estaria em constante progresso para melhor e, buscando 
identificar um evento que possa apontar para uma resposta positiva, ou seja, um sinal de progressão do homem, cita a Revolução Francesa, como uma comprovação da "disposição moral da humanidade".

De fato, o movimento revolucionário francês, de 1789, como citado por Batista (2016, p. 153) foi a última e mais longa revolução, das que ocorreram entre os séculos XVII e XVIII, tendo como motor principal a insatisfação da burguesia com o governo absolutista, aliado ao seu interesse em unir o poder econômico, que então era detentora, com o poder político para então atar "as amarras impostas ao comércio e à manufatura e deixando de sustentar os luxos da nobreza parasitária” (BATISTA, 2016, p. 153).

Antes mesmo da Declaração dos Direitos do Homem e do Cidadão, de 1789, Fonseca (2006, p. 11) cita, como fonte inspiradora, a Declaração de Direitos do Bom Povo da Virgínia.

A tomada do poder pelos burgueses, causou uma ruptura com o chamado "Antigo Regime" (BATISTA, 2016, p. 16) e inicia-se um modelo estatal onde seu único escopo era a garantia jurídica da propriedade e das liberdades individuais, era o chamado Estado Liberal, "possuindo uma estrutura restrita à repressão de qualquer tentativa de supressão de tais direitos" (BATISTA, 2016, p. 155).

Tal configuração estatal possuía grande influência Iluminista, tendo como efeito o grande reconhecimento dos direitos considerados de primeira dimensão, ou seja, os direitos de liberdade (PACHU, 2015, p. 17).

A consagração de tais direitos perante o Estado, traz a visão das teorias contratualistas dos séculos XVII e XVIII que objetivavam a justificação de um ente estatal, onde o soberano exerceria sua autoridade com o respeito aos direitos do homem, ou seja, era a "ideia da supremacia do indivíduo sobre o Estado" (PINHEIRO, 2006, p. 103).

Com o quadro do Estado Liberal, nota-se também uma alteração da forma de produção, advinda principalmente com a Revolução Industrial. Batista (2016, p. 153) descreve que esta revolução "marcou a passagem do protocapitalismo comercial para o capitalismo industrial", considerando que se deixa o modelo das Corporações de Ofício para uma produção mecanizada, com grande diminuição da necessidade da força de trabalho do homem.

Os trabalhadores deixam de possuir o controle da sua força de trabalho, pois começa a utilização das máquinas a vapor e a produção passa a ser mecanizada, alterando radicalmente a relação entre capital e trabalho. Dessa forma, a propriedade dos meios de produção era somente do burguês rico (BATISTA, 2016, p. 153-154). 
Ocorre um maior desenvolvimento das cidades, fazendo com que seja atraída uma população que estava vivendo nas antigas cidades, onde ainda se utilizava o sistema feudal.

Dessa forma, aos poucos é dissolvida a estrutura social até então vigente, ou seja, senhor do feudal e do servo e apresenta-se a "divisão capitalista de classes" (BATISTA, 2016, p. 151).

O burguês, o homem livre que pratica o comércio e acumula o capital (BATISTA, 2006, p. 151), enriquece de forma súbita, atingindo níveis jamais vistos desde então (FERREIRA FILHO, 2012, p. 60), causando a acumulação primitiva de capital (MARX, 1988, p. 251).

Este movimento da sociedade produtiva, fruto do Estado Liberal fez surgir uma grande desigualdade social, pois estimulou-se "a exploração da classe dominante sobre os operários" (PACHU, 2015, p. 17).

A sustentação política para a desigualdade cada vez mais patente era o liberalismo, considerando que o detentor do capital e o trabalhador deveriam, imbuídos cada um de sua autonomia de vontades, ou seja, este estabelecer a venda de sua força de trabalho e aquele, o preço, conforme as leis do capitalismo (oferta e procura) (BATISTA, 2016, p. 154).

A motivação, portanto, decorreu da livre iniciativa num mercado concorrencial e diante de um Estado abstencionista (FERREIRA FILHO 2012, p. 60).

O capitalismo, desenvolvido ao final do século XIX e início do século XX, fez surgir a urbanização e centros industriais, mas na medida que havia um maior ritmo da produção, alastrava-se a miséria dentre aqueles que somente possuíam a sua mão de obra como fonte de sobrevivência (FONSECA, 2006, p. 11-12).

A Revolução Industrial manteve seu crescimento, considerando o aumento das inovações tecnológicas, notadamente com a substituição do vapor pela eletricidade, no final do século XIX, fazendo com que houvesse um aumento da mecanização da produção, passando o trabalhador a um simples operador de uma única função (BATISTA, 2016, p. 153154).

Ademais, diante do grande número de pessoas à disposição para o trabalho (grande oferta), os salários eram baixos, não havendo, portanto, a capacidade de absorção da mão de obra disponível, formando uma massa de desempregados (FERREIRA FILHO, 2012, p. 60).

Este quadro de deterioração social era nominado como a Questão Social, portanto, seria uma fotografia da forma com que os trabalhadores estavam expostos ante um avanço do capitalismo (FERREIRA FILHO, 2012, p. 59-60). 
Pachu (2015, p. 17) relata a existência de "enorme desigualdade na sociedade, em consequência da não intervenção do Estado na vida econômica e social da população, estimulando a exploração da classe dominante sobre os operários”.

Batista (2016, p. 154) relata que a autonomia da vontade, vigente até o momento, fazia com que os trabalhadores:

Vendessem sua força de trabalho por até vinte horas diárias, bem como que o trabalho fosse feito por mulheres, inclusive as grávidas eram comuns os partos dentro da fábrica, durante o horário de trabalho -, e crianças, mesmo as muito pequenas, a quantidade de acidentes fatais e mutilantes era muito alta, agravando ainda mais o cenário.

Diante da situação existente, claramente foi notado que a garantia de direitos, exercidos contra o Estado (primeira dimensão) não era mais suficiente "para permitir a plena realização do indivíduo em seu ambiente social” (PINHEIRO, 2006, p. 103).

Pinheiro (2006, p. 103) aponta que o sucesso da Revolução Russa, a partir de 1917 e o modo de produção socialista passaram a ser a inspiração e a motivação da classe trabalhadora em todo o mundo, com a condenação do atual regime e reivindicando melhores condições de trabalho.

Batista (2016, p. 157) assinala que tal movimento ameaçava a existência do capitalismo, considerando que uma das bases da Revolução Russa era o Manifesto Comunista, de Marx e Engels, de 1848 e, simbolicamente, este finaliza com a conclamação de união dos operários: Proletários de todos os países, uni-vos! (MARX, 1999, p. 65).

É notado como um perigo real quando da vitória da revolução bolchevique em 1917, despertando a necessidade de examinar a forma mais eficiente de conter a mobilização dos trabalhadores (BATISTA, 2016, p. 162).

A movimentação dos trabalhadores teve como alvo principal o Estado, este deveria deixar o seu caráter até então inerte, liberal, para possuir uma posição mais ativa para a garantia do respeito aos direitos sociais (COMPARATO, 2012, p. 152). O Estado deveria ter a obrigação de fazer, de realizar uma prestação, ser o interventor na dinâmica social que se apresentava.

Tais direitos, chamados de segunda dimensão possuem natureza programática e, portanto, fazem com que haja a necessidade de uma atuação estatal para que ele seja efetivado 
(PACHU, 2015, p. 17). Faz-se necessário que o Estado tenha que reunir meios necessários para a satisfação da comunidade (TOLFO, 2013, p. 36).

Os direitos individuais e sociais, descreve que os primeiros exigem obrigações "puramente negativas, que implicam abstenção de determinados comportamentos", enquanto que os segundos só podem ser realizados se for imposto a outros "um certo número de obrigações positivas" (BOBBIO, 1992, p. 21).

Os direitos de segunda dimensão, ou seja, os econômicos, sociais e culturais "realçam o princípio da igualdade entre os homens. Estão relacionados à passagem do Estado liberal (de cunho individualista) para o Estado social (focado na proteção dos hipossuficientes e na busca da igualdade material)" (PAULO; ALEXANDRINO, 2010 apud TOLFO, 2013, p. 3536).

Nos domínios da solidariedade social o individualismo tem sua correção pelo reconhecimento da legitimidade das intervenções do Estado (BURDEAU, 1996 apud CURY, 1998, p. 2).

Para a conferência de natureza social a uma constituição é necessário o reconhecimento expresso do Estado, além de garantia de liberdade clássicas, que ela ocorra para o desfrute de direitos e garantias (PINHEIRO, 2006, p. 104).

Comparato (2012, p. 44) afirma que o principal benefício que a humanidade obteve com o movimento socialista foi o "reconhecimento dos direitos humanos de caráter econômico e social", tendo como titular, não o ser humano, mas sim "o conjunto dos grupos sociais esmagados pela miséria, a doença, a fome e a marginalização".

E, neste sentido, "é ao socialismo que se deve a maior influência vivificadora nas Declarações de Direitos dos nossos dias” (MIRANDA, 1932 apud CURY, 1998, p. 3).

A Constituição do México, neste sentido, é a pioneira no estabelecimento da “desmercantilização do trabalho", pois "firmou o princípio da igualdade substancial de posição jurídica entre os trabalhadores e empresários na relação contratual (...)" (COMPARATO, 2012, p. 143).

\section{A CONSTITUIÇÃO DO MÉXICO DE 1917}

Como já mencionado, as Constituições do México, de 1917 e a de Weimar, de 1919 são apontadas como as primeiras formatações estatais em que os direitos sociais, os direitos de segunda dimensão, são previstos. 


\section{A INTERVENÇÃO ESTATAL COMO PRESSUPOSTO NECESSÁRIO PARA A EFETIVIDADE E MANUTENÇÃO DOS DIREITOS SOCIAIS}

No entanto, importante advertir que: “[...] seria uma esquematização simplista a afirmação de que as Constituições do século XIX foram todas puramente liberais e as Constituições do século XX marcadamente sociais" (DA SILVA, 1991, apud PINHEIRO, 2006, p. 104).

Cita-se como exemplos de tais constituições liberais com algumas regras de caráter social, a da Venezuela de 1812 (Constituição da Província de Barcelona), a Constituição Francesa de 1848 e a Constituição Suíça de 1874.

O legislador mexicano se inspirou em legislações sociais de outros países como França, Bélgica, Itália, Estados Unidos, Austrália e Nova Zelândia (DE LA CUEVA, 1960, apud PINHEIRO, 2006, p. 119-120). No entanto, inegável que a Constituição Mexicana é a grande inovadora jurídica, considerando a sua abrangência e o número de regras sociais que ali se previu.

Comparato (2012, p. 141) aponta que o texto constitucional mexicano possui importância histórica, pois na Europa a consciência que os direitos sociais possuem caráter de direito humano só ocorreu após a I Guerra Mundial.

O texto constitucional mexicano tem a Revolução Mexicana de 1910 como um verdadeiro alarme que resultou na Constituição de 1917 (GARGARELLA; GUEDES; PADUA, 2016, p. 35).

Os direitos previstos na Constituição mexicana refletem as reivindicações revolucionárias do grupo Regeneración, liderado por Ricardo Flores Magón, com grande inspiração das ideias anarcossindicalista de Mikhail Bakunin, que eram contrários à ditadura de Porfírio Diaz e, em 1906, o referido grupo apresenta um manifesto "que viriam a ser as linhas-mestras do texto constitucional de 1917" (COMPARATO, 2012, p. 140).

Entusiasmados com as ideias do oposicionista da Ditadura Francisco Madero, especialmente Emílio Zapata, um chefe camponês de grande importância, comanda, ao sul do país, um importante número de homens armados com fuzis e facões e, ao norte, destacam-se Pacho Villa e Pascual Orozco (PINHEIRO, 2006, p. 108).

O ditador Diaz renúncia e foge em 1911, sendo Madero eleito Presidente, mas não consegue promover as modificações desejadas, sendo este assassinado pelo general Victoriano Huerta, a quem Madero destacou para derrubar Zapata, que liderava uma revolta com seus homens contra o Presidente (PINHEIRO, 2006, p. 108).

Huerta, sob pressão revolucionária renuncia em julho de 1914 e passa o poder para Venustiano Carranza, que deseja institucionalizar e regulamentar os anseios da revolução e, em 1917 é promulgada a Constituição (PINHEIRO, 2006, p. 109). 
$\mathrm{Na}$ análise do texto constitucional, apesar o seu caráter social, é também notada a preservação dos direitos de primeira dimensão, ou seja, aqueles ligados à liberdade, tendo o Capítulo I o título de "Das Garantias Individuais" (PINHEIRO, 2006, p. 110).

A Constituição do México, de 1917 é aquela que, pela primeira vez alça para a qualidade de direitos fundamentais aos direitos trabalhistas, juntamente com as liberdades individuais e os direitos políticos (COMPARATO, 2012, p. 140).

A Constituição Mexicana reservou um título (IV) somente para regular as disposições sobre o trabalho e a previdência, sendo defendido, portanto, que tal diploma seria o inaugurador do Direito Constitucional do Trabalho (PINHEIRO, 2006, p. 111).

Destaca-se que o art. 123 trouxe o limite da jornada de trabalho em 8 horas (inciso I) e 7 horas para trabalho noturno (inciso II), impossibilidade de contratação de menores de 12 anos (inciso III), descanso de 1 dia para cada 6 dias trabalhados (inciso IV), salário igual sem distinção de sexo ou nacionalidade (VII), responsabilidade do empregador quando o empregado for vítima de acidente do trabalho ou de doença ocupacional (inciso XIV), etc.

Notam-se ainda previsões acerca da previdência, pois o inciso XXIX declara de utilidade social as Casas de Seguros Populares de invalidez, de vida, de cessação involuntária de trabalho, de acidentes e outros fins, devendo o Governo Federal e os demais Estados fomentar a organização de tais instituições.

Pode ser notado, portanto, que o referido art. 123 insere regras que, posteriormente, servem de modelo para a construção de um moderno direito laboral (GARGARELLA; GUEDES; PADUA, 2016, p. 35).

Apesar do seu espírito vanguardista que hoje se reverencia, alguns autores apontam que seu caráter revolucionário obteve somente força regional, ou seja, perante a América Latina.

A Constituição do México, de 1917 “decisivamente, mudou a história do constitucionalismo Latino-Americano", considerando que a maioria dos países da região passaram incluir longas listas de direitos sociais, tais como: o Brasil modificou sua constituição em 1937; a Bolívia em 1938; Cuba em 1940; Uruguai em 1942; Equador e Guatemala em 1945; e Argentina e Costa Rica em 1949 (GARGARELLA; GUEDES; PADUA, 2016, p. 35).

Pinheiro (2006, p. 119), utilizando a expressão de Karl Loewenstein (1970), reforça a visão da Constituição mexicana não ter sido o "equipamento-padrão" dos demais textos constitucionais, considerando o fato de que a questão social, e as normas trabalhistas, não 
eram desconhecidas na Europa, bem como, a escassa produção doutrinária, impedindo que houvesse uma grande difusão das "conquistas sociais alcançadas em continente americano".

A repercussão mais ampla do texto constitucional mexicano de fato não existiu. A Europa desconheceu à época a legislação e assim, os olhos do mundo foram postos para a Constituição de Weimar, até mesmo pela grande literatura que se seguiu, enquanto que os estudos doutrinários no México foram escassos (OLIVEIRA, 1991 apud PINHEIRO, 2006, p. 121).

A constituição de Weimar foi "prepoderante em tema de inauguração da fase do constitucionalismo social", tendo influenciado as demais constitucionais. Dessa forma, conclui que o texto constitucional mexicano "não obstante inspirador, culminasse por configurar um modelo de referência quase que regional, muito adequado à realidade daquele país, mas pouco universalizante" (PINHEIRO, 2006, p. 119-121).

Quanto à repercussão no Brasil, em uma simples comparação entre o texto constitucional mexicano, de 1917 e a Constituição brasileira, de 1934, esta a primeira a promover, em nível constitucional, direitos sociais, pode-se notar uma grande inspiração deste constituinte naquele diploma.

Não se nota tão somente o sistema de rol de direitos, mas sim direitos muito próximos aos dos mexicanos, tais como, trabalho com limite de 8 horas, salário mínimo, proibição de diferença salarial por motivo de idade, sexo, nacionalidade ou estado civil e descanso semanal.

É notável, entretanto, a modernidade da constituição mexicana, pois temas bastante relevantes, tais como, como a responsabilidade do empregador em casos de doença ou acidente, pagamento de horas extras com adicional de $100 \%$ e direito de greve estão ali previstos.

As demais constituições brasileiras, de certa maneira, mantiveram tais direitos, aprimorando o rol de direitos sociais, atingindo o seu ápice no texto constitucional de 1988.

Dessa forma, apesar de não ter tido repercussão mundial, a Constituição do México de 1917, possui grande importância na passagem do modelo do Estado liberal para o social.

Utilizando o exemplo mexicano, as constituições Latino-Americanas, posteriores passaram a prever um rol de direitos sociais e assim, por meio da linguagem jurídica, foi a maneira que a região expressou as grandes mudanças sociais ocorridas até a primeira metade do século XX "nomeadamente a incorporação da classe trabalhadora como um decisivo ator político e econômico" (GARGARELLA; GUEDES; PADUA, 2016, p. 35-36). 


\section{A CONSTITUIÇÃO DE WEIMAR DE 1919}

A importância dada à Constituição de Weimar, como sendo o "equipamento-padrão" (LOEWENSTEIN, 1970 apud PINHEIRO, 2006, p. 120), por ter influenciado as demais constituições no século XX, se deu em razão da sua promulgação ter ocorrido na Europa e ainda por ter natureza mais abstrata, ou seja, não tendo sido tão específica às necessidades locais, como a do povo mexicano (PINHEIRO, 2006, p. 122).

O contexto social que vivia a Alemanha, quando das eleições para a constituinte, era de grande crescimento urbano-industrial, com evolução de uma classe operária e militante, constituída posteriormente ao sucesso de Bismarck na guerra Franco-Prussiana, decorrente da criação do Império Alemão Confederado (CURY, 1998, p. 2).

Em 1841 um terço da população alemã viva em cidades e, em 1910 esta proporção era dois terços. A população de Berlim, em 1867, era de 700.000 habitantes e, em 1913, já eram 4.000.000, sendo que, em 1907, 44,3\% eram operários, sendo 68\% assalariados (ALMEIDA, 1999, p. 9-10).

Esta população urbano-industrial é liderada pelo Partido da Social Democracia, que busca reformas de cunho social, desenvolvendo ainda forte ideologia nacionalista (CURY, 1998, p. 2).

A constituinte reuniu-se na cidade Weimar e, na elaboração da nova constituição, claramente houve grande influência da revolução bolchevique, de 1917, bem como, a presença do Partido da Social-Democracia, considerando a forte aproximação do ideário socialista (CURY, 1998, p. 3).

A Constituição de Weimar foi realizada em meio de um "compromisso entre a direita burguesa e os socialdemocratas", com o intuito de livrar o país de uma revolução socialista (BATISTA, 2016, p. 165).

Esta revolução, de curta duração, ocorreu como um reflexo da I Guerra Mundial, pois a população enfrentava desabastecimento, considerando que a produção industrial estava direcionada para o enfretamento bélico (BATISTA, 2016, p. 163).

O Partido Social-Democrata perde alguns de seus membros, que fundam o Partido Socialista Independente, com oposição à guerra, com objetivo de estender a revolução bolchevique à Europa (BATISTA, 2016, p. 164).

Ao fim de protestos, que se iniciou no porto de Kiel, passando por Stuttgart, Hamburgo e Berlim, foram convocadas eleições para formação da assembleia constituinte, não tendo os comunistas apresentado candidatura, fazendo com que os moderados fossem 
"obrigados a firmar aliança com partidos burgueses, a qual conseguiu abarcar setenta e cinco por cento dos votos, de forma que pode conduzir o processo constituinte" (BATISTA, 2016, p. 165).

Havia uma movimentação da esquerda radical para tomar o poder "à moda bolchevique" e, por não haver clima em Berlim, os constituintes reuniram-se em Weimar (FERREIRA FILHO, 2012, p. 66).

Diante do referido histórico, Batista (2016, p. 166) aponta que a Constituição de Weimar não poderia ser apontada como um "monumento aos direitos dos trabalhadores, mas um instrumento de perpetuação da dominação contra uma tentativa de emancipação que quase foi bem-sucedida".

A Constituição de Weimar possui, basicamente, duas partes. Uma que regula a estrutura administrativa do Estado e seus poderes e a segunda que regula os direitos sociais, tais como, educação, saúde, dignidade da relação trabalhista, proteção à infância e à maternidade (AUAD, 2008, p. 338-339).

Sob este aspecto, é esta segunda parte do texto constitucional que representa a grande alteração, "a mudança do status social vigente à época, a qual decorreria da distribuição de riquezas decorrente da reforma social” (AUAD, 2008, p. 339).

A nova Constituição: "seria um caminho de transição pacífica para a construção do Estado Social, de bases marxistas, o qual superaria definitivamente o modo de produção capitalista" (HELLER, 1985 apud AUAD, 2008, p. 339).

E, de fato, apesar da sua curta vigência (até o início do regime nazista, em 1933), representa um verdadeiro marco para "reconhecimento histórico dos direitos sociais como direitos fundamentais e complementares aos direitos civis e políticos" (AUAD, 2008, p. 340).

A Constituição de Weimar "exerceu decisiva influência sobre a evolução das instituições políticas em todo o Ocidente", forjando o Estado da democracia social uma estrutura mais elaborada, tendo suas linhas-mestras traçadas pela Constituição mexicana, de 1917 (COMPARATO, 2012, p. 151).

A estrutura da Constituição de Weimar, imantando os direitos sociais com a força de norma constitucional iniciou uma conscientização, no Ocidente, sobre o dever do estado em garantir a dignidade humana (AUAD, 2008, p. 352).

No entanto, houve manifestação sobre uma "contradição absoluta entre os dois livros", ou seja, entre as duas partes do texto constitucional, pois um apresentaria uma organização liberal de Estado e o outro estariam prestigiados direitos de natureza socialista (SCHMITT, 1982 apud PINHEIRO, 2006, p. 116). 
E, comparando à Constituição do México, de 1917, a Constituição de Weimar possui uma preocupação menos regional e mais abstrata e universalizante, sendo mais inspiradoras às demais nações em razão de sua adaptação às necessidades de cada uma (PINHEIRO, 2006, p. 121).

Quanto aos direitos de segunda dimensão é percebível uma "nítida diferenciação entre os dois textos quanto aos temas sociais prioritários, eleitos pelos diplomas constitucionais para os fins de outorgar-se especial proteção". O texto mexicano concentrou-se de maneira sensível na solução das questões agrárias (art. 27) e dos direitos trabalhistas (art. 123) (PINHEIRO, 2006, p. 118).

A Constituição de Weimar, além de direitos trabalhistas e reconhecimento da função social da propriedade, apresenta uma sistematização de outros direitos como educação pública, obrigatória e gratuita, previdência social e até mesmo incentivo à pesquisa (PINHEIRO, 2006, p. 120).

O caráter social da Constituição de Weimar adveio entre os movimentos sociais internos e as consequências em torno do fim da primeira Guerra Mundial (ALMEIDA, 1987, apud CURY, 1998, p. 3).

Neste sentido, foi procurado um pacto que pudesse agregar posições entre o "arco ideológico" entre a extrema direita à extrema esquerda, "onde se digladiavam os partidos ligados à social-democracia, os ligados ao Centro Católico e os fomentadores do nacionalismo mais extremado" (CURY, 1998, p. 3).

Enquanto a Constituição do México, de 1917, não obteve uma grande repercussão mundial, muito em razão pela ausência de doutrinadores. Na Alemanha, a repercussão ocorreu porque à época do texto de Weimar "floresceu uma plêiade de intelectuais, cientistas e artísticas cujas obras transcendem os limites da Alemanha", tais como, Heiddegger, Weber, Bauhauss e Kelsen (estes destaques nas ciências humanas e sociais) (CURY, 1998, p. 10).

Dessa forma, houve grande produção doutrinária acerca do novo texto e que "fez correr pelo mundo as vitórias e as vicissitudes do novo texto republicano de 1919" (PINHEIRO, 2006, p. 122).

Sobre a importância da referida Constituição, Guerra Filho (2005 apud FONSECA, 2006, p. 140) aponta que:

A Constituição de Weimar produziu uma transformação de significados dos direitos fundamentais, passando de um Estado de Direito Liberal burguês a um Estado de direito social [...] e os direitos fundamentais 
são descobertos agora com um significativo fator de integração na esfera da vida estatal e social e como meio também de desenvolvimento do Estado e da sociedade.

Na Constituição de Weimar, a efetivação dos direitos sociais passou a ser de responsabilidade estatal e, dessa forma, o Estado poderia ser cobrado por uma atuação positiva (AUAD, 2008, p. 339).

Dentre os direitos de liberdade, postos na referida Constituição, destacam-se os de igualdade entre homens e mulheres, direito à nacionalidade, liberdade de circulação no território e para o exterior, direitos das minorias, inviolabilidade de domicílio e liberdade de manifestação e pensamento, voto secreto, liberdade de reunião, de associação e de sindicalização (PINHEIRO, 2006, p. 111).

Quanto aos direitos considerados de segunda dimensão, destacam-se à maternidade, à educação, à pensão para família em caso de falecimento e direito à aposentadoria, direito ao ensino, material escolar, direito a uma habitação sadia, direito ao trabalho, proteção à maternidade, à velhice, às debilidades e aos acasos da vida, mediante sistema de seguros, com a direta colaboração dos segurados (PINHEIRO, 2006, p. 116).

À classe operária menciona-se ainda "um mínimo geral de direitos sociais", segurodesemprego e direito à participação, mediante Conselhos - Conselhos Operários e Conselhos Econômicos -, no ajuste das condições de trabalho e do salário e no total desenvolvimento econômico das forças produtivas, inclusive mediante apresentação de projeto de lei" (PINHEIRO, 2006, p. 117).

$\mathrm{Na}$ Constituição de Weimar, o art. 162, é considerado como uma "antecipação histórica" quanto à preocupação de regras mínimas internacionais do trabalhado assalariado e o art. 163 evidencia o dever do Estado em manter uma política de pleno emprego (COMPARATO, 2012, p. 153).

Apesar do seu avanço, algumas críticas foram tecidas a este texto constitucional.

A Constituição de Weimar não era dotada de aplicabilidade e que deveria ser desconsiderada do ordenamento jurídico, pois "não garantia um mínimo de conteúdo decisório ao aplicador do Direito" (SCHMITT, 1996 apud AUAD, 2008, p. 339-340).

Tais visões de natureza conservadora, foram os motivos que extinguiram a possibilidade de implantação do modelo proposto pelo texto constitucional (AUAD, 2008, p. 340): 
O diálogo em prol integração social e fortalecimento da democracia foram substituídos por um Estado Totalitarista que se instalou no poder com a promessa da integração nacional baseada na ideologia da segregação racial, e que dotou o partido nazista de poderes até mesmo mais amplos que o Estado

Apesar do avanço do texto, o desfecho de Weimar se mostrou trágico, pois: “A Constituição de Weimar era considerada pela direita como obra não-alemã, traição cometida por judeus, inspirados pelo judeu Hugo Preuss, importada dos países anglo-saxônicos e imposta pela Entente” (TRAGTENBERG, 1988 apud CURY, 1998, p. 9).

Cury (1998, p. 9) complementa afirmando que: "Parte das esquerdas também a acusava de traição à revolução operária, de se deixar tutelar pelo Exército e de fazer sucessivos pactos desfavoráveis ao avanço do socialismo”.

No entanto, analisando os avanços sociais do texto constitucional de Weimar, pode-se notar que a referida Constituição "representa um amadurecimento intelectual em relação à conscientização de que o bem-estar social é condição essencial que pressupõe a conquista dos demais direitos" (AUAD, 2008, p. 340).

Ocorre, no entanto, uma readaptação do capitalismo, considerando os "novos eventos sociopolíticos contestatórios da ordem vigente". Ocorrendo uma contemplação de interesses de posicionamentos de esquerda e direita (CURY, 1998, p. 3).

É inegável que a Constituição Weimar tenha influenciado as constituições modernas e, claramente isso também isso ocorreu no Brasil, na Constituição de 1934, juntamente como a já mencionada Constituição do México de 1917.

Clark (2008, p. 214), citando as constituições mexicanas e alemãs aponta que a Constituição do Brasil de 1934, seguiu "os ventos dos Estados Sociais, com suas políticas econômicas neoliberais de regulamentação".

A Constituição de 1934 "inseriu a democracia social” no Brasil (BONAVIDES, 1990 apud FONSECA, 2006, p. 169) e isso é notado no preâmbulo, pois estabelece "um regime democrático, que assegure à Nação a unidade, a liberdade, a justiça e o bem-estar social e econômico" (CAMPANHOLE A.; CAMPANHOLE H., apud FONSECA, 2006 p. 169).

Para Bonavides (1991, p. 325) a Constituição do Brasil de 1934 possuiu a "admirável marca social dos direitos do homem". No entanto, menciona que ela teve "a mesma sina da sua matriz europeia, a de Weimar, aquela onde foram beber a inspiração os continentes que nos reconduziram à Europa", pois pereceu: "submersa nas agitações que abalaram o País, 
efeitos de uma efervescência ideológica de cunho revolucionário, da qual colheu a contrarreforma ensejo de desferir o golpe de Estado, de 1937 (BONAVIDES, 1991. p. 325).

No entanto, a conquista dos direitos sociais, no Brasil, chega ao auge em 1988, pois traz extenso rol de direitos sociais e prevê uma participação ativa do Estado para sua garantia, mas também expôs a tensão entre a liberdade e a igualdade, pois o caput do art. 170 aponta que a ordem econômica é fundada na valorização do trabalho humano e na livre iniciativa (KHAMIS, 2015, p. 172).

Com o reconhecimento deste conflito e para evitar que o poder econômico possa impedir a igualdade, a dignidade do trabalhador, para a promoção do lucro, o Estado é chamado a intervir, nos limites da legalidade, quando ocorrer violação do necessário equilíbrio de interesses (KHAMIS, 2015, p. 172).

\section{CONSIDERAÇÕES FINAIS}

Retomando o questionamento de Kant, trazido no início deste trabalho, ou seja, se o gênero humano estaria em constante progresso para melhor, após apresentada a evolução histórica do modelo liberal para o social, adotado atualmente por uma grande maioria das nações, a resposta é positiva.

O Estado, como participante ativo na sociedade, garantindo direitos sociais, provoca a indução de comportamentos que devem visar o bem-estar e isso faz com que haja um progresso efetivo das relações e da evolução em conceitos importantes da vida como trabalho, saúde, educação, previdência etc.

As constituições do México e a de Weimar, acima mencionadas, tiveram a importância de revelar, em grau constitucional, direitos a serem garantidos pelo Estado e assim, promover uma evolução no que se entendia até então como direitos necessários à sobrevivência e dignidade.

Mostrou-se que, no ápice do liberalismo, os atores sociais, quando desiguais materialmente, fracassaram na conquista de um equilíbrio de forças, pois o mais forte tende a sempre abusar do mais fraco.

Portanto, há necessidade de um ente, com legitimidade e força para que encare tal situação e equilibre a balança social de forma a trazer amparo e justiça para os componentes da relação. 
É importante retomar a consciência sobre o passado e mostrar a importância de conquistas sociais, pois atualmente existe forte movimento para uma flexibilização de direitos sociais, ou até mesmo a sua exclusão, sob os mais diversos pretextos.

No entanto, quando se olha no retrovisor da história, é notado que tais direitos foram forjados com muita luta e obtiveram o seu reconhecimento na evidência da sua total pertinência e sua necessidade para que o cidadão tenha preservada a sua dignidade.

É até mesmo contraditório que, no Brasil, tal movimentação liberal seja feita diante do mais avançado texto constitucional que nosso país já teve em matéria de direitos sociais.

A Constituição de 1988 é uma importante certidão de nascimento do Brasil como país que assegura um grande elenco de direitos sociais, sempre na intenção final de preservar valores sociais e a dignidade, dois dos mais importantes fundamentos da República.

O reconhecimento da necessidade da preservação de direitos sociais, a consciência da sua importância e a sua luta pela conquista e manutenção, revela sobremaneira, a maturidade de uma nação.

Claramente que não é a intervenção estatal na garantia de direitos sociais que causa crises econômicas ou empobrece um povo, mas sim é o que assegura a verdadeira democracia. 


\section{REFERÊNCIAS}

ALMEIDA, Angela Mendes de. A República de Weimar e a Ascenção do Nazismo. São Paulo: Ed. Brasiliense, 1999.

AUAD, Denise. Os Direitos Sociais na Constituição de Weimar Como Paradigma do Modelo de Proteção Social da Atual Constituição Federal Brasileira. Revista da Faculdade de Direito da Universidade de São Paulo, São Paulo, v. 103, p. 337/355, jan./dez. 2008.

BATISTA, Flávio Roberto. Apontamentos Críticos Para Uma História do Direito Previdenciário no Ocidente Capitalista. Revista da Faculdade de Direito da Universidade de São Paulo, São Paulo, v. 1 n. 11, p. 143-176, jan./fev. 2016.

BERCOVICI, Gilberto. As Possibilidades de Uma Teoria do Estado. Revista da Faculdade de Direito da UFMG, Belo Horizonte, n. 49, jul./dez. 2016.

BOBBIO, Norberto. A Era dos Direitos. Tradução de Carlos Nelson Coutinho. Rio de Janeiro, 13 ${ }^{\text {a }}$ Tiragem: Campus, 1992.

BONAVIDES Paulo; ANDRADE Paes de. História Constitucional do Brasil. Rio de Janeiro: Paz e Terra, 1991.

BRASIL. Constituição (1934). Disponível em

http://www.planalto.gov.br/ccivil_03/constituicao/constituicao34.htm. Acesso em: 12 janeiro 2018.

CLARK, Giovani. Política Econômica e Estado. Revista de Estudos Avançados USP, São Paulo, vol. 22, n. 62, 2008.

COMPARATO, Fábio Konder. A Afirmação Histórica dos Direitos Humanos. $7^{a}$ ed. São Paulo: Saraiva, 2012.

CURY, Carlos Roberto Jamil. A Constituição de Weimar: Um Capítulo Para a Educação. Revista Educação e Sociedade, Campinas, vol. 19, n. 63, ago. 1998.

FERREIRA FILHO, Manoel Gonçalves. Direitos Humanos Fundamentais. 14 ${ }^{\mathrm{a}}$ ed. São Paulo: Saraiva, 2012.

FONSECA, Maria Hemília. Direito do Trabalho: Um Direito Fundamental No Ordenamento Jurídico Brasileiro. Tese (Doutorado em Direito) - Pontifícia Universidade Católica. São Paulo, 2006.

GARGARELLA, Roberto; PÁDUA, Thiago e GUEDES, Jefferson. Constitucionalismo Latino-Americano: Direitos Sociais e a "Sala de Máquinas" da Constituição. Universitas JUS, Brasília, v. 27, n. 2, p. 33-41. 2016.

KHAMIS, Renato Braz Mehanna. O fundamento ético da regulação da regulação econômica e seus limites no âmbito do estado constitucional. Opinión Jurídica, Medelín, v. 14, n. 28, p. 159-176, jul./dez. 2015. 
MARX, Karl. O Capital - Crítica da Economia Política. Volume I. Livro Primeiro. O Processo de Produção do Capital. Tomo 2. $3^{\text {a }}$ ed. São Paulo: Nova Cultura. 1988.

MARX, Karl; ENGELS, Friedrich. O Manifesto Comunista. Ed. Ridendo Castigat Moraes. Ebook. 1999.

MÉXICO. Diário Oficial da República Mexicana (1917). Disponível em:

http://www.diputados.gob.mx/LeyesBiblio/ref/cpeum/CPEUM_orig_05feb1917.pdf. Acesso em: 14 janeiro 2018.

PACHU, Clésia Oliveira. SALES, Juliana Maria Araújo. Direitos Sociais e as Políticas Públicas como Mecanismo de Efetivação. In: PACHU, Clésia Oliveira. Direitos Sociais: O Artigo $6^{\circ}$ da Constituição Federal e sua efetividade. Paraíba: Eduepb, 2015.

PINHEIRO, Maria Claudia Bucchianeri Pinheiro. A Constituição de Weimar e os Direitos Fundamentais Sociais - A preponderância da Constituição da República Alemã de 1919 na inauguração do constitucionalismo social à luz da Constituição Mexicana de 1917. Revista de informação legislativa, Brasília, vol. 43, n. 169, jan./mar. 2006.

TOLFO, Andreia Cadore. Direitos Humanos e a Construção da Cidadania. Vivências:

Revista Eletrônica de Extensão da URI, Erechim, vol. 9, n. 17, p. 33-43, out. 2013. 